Palimpsesto Vol. 10, № 17 (enero-junio, 2020): 197-220

Universidad de Santiago de Chile, ISSN 0718-5898

María Florencia Antequera

CONICET/Universidad Católica Argentina/Universidad Nacional de Rosario

mfantequera@hotmail.com

\title{
La beca Guggenheim, las credenciales norteamericanas y la arquitectura euríndica. Una aproximación al epistolario inédito de Ángel Guido a Ricardo Rojas (1925-1955)*
}

\author{
Guggenheim Fellowship, American Credentials and "Eurindica" \\ Architecture. An Approach to the Unpublished Collected Letters \\ between Angel Guido and Ricardo Rojas (1925-1955)
}

\begin{abstract}
Resumen
Esta comunicación busca atender a la correspondencia que Ángel Guido (Rosario, 1896-1960) y Ricardo Rojas (San Miguel de Tucumán, 1882- Buenos Aires, 1957) trocaron entre 1931 y 1933, en torno al hecho meridiano que significó, para el itinerario intelectual del arquitecto rosarino, el obtener la prestigiosa beca Guggenheim y, consecuentemente, viajar a EEUU. Se trata entonces de interrogar una práctica de escritura junto a sus intervenciones ideológicas, a través de ese continente autobiográfico (Antières y Dabbadie, 2019) o laboratorio de ideas (Maíz, 2018), que conforma esta selección de piezas pertenecientes al conjunto mayor del epistolario inédito (1925-1955). Para decirlo en otros términos, procuramos cartografiar la articulación de lo individual -qué buscaba el arquitecto con la obtención de la beca, qué cambió en su horizonte intelectual, cuáles son los resortes que se mueven en su proyección profesional con el viaje a EEUU - con un plafón más abarcativo donde la pregunta por una arquitectura americana, emancipada y de extracción euríndica se constituía en rectora.
\end{abstract}

Palabras claves: Epistolario, Ángel Guido, Ricardo Rojas, beca Guggenheim, arquitectura euríndica.

\footnotetext{
Abstract

This paper puts attention on the collected letters that Angel Guido (Rosario, 1896-1960) and Ricardo

* Esta comunicación se inscribe en el marco de estudios posdoctorales realizados en la Universidad Federal de Santa Catarina (Florianópolis) y de las investigaciones sobre epistolarios que venimos desarrollando con el Grupo de Escrituras y Representaciones del Pasado (GEREP)-IH IDEHESI CONICET, gracias a una beca posdoctoral otorgada por este organismo de pesquisa. Agradezco vivamente los intensos diálogos con el Dr. Raúl Antelo (UFSC- CNPq) sobre Ángel Guido así como también la lectura atenta y enriquecedora de la Dra. Liliana Brezzo (IH IDEHESI CONICET). Manifiesto, de igual modo, mi gratitud con el Instituto de Investigaciones de la Casa Museo Ricardo Rojas por permitirme tomar contacto con las piezas documentales que aquí se analizan.
} 
Rojas (San Miguel de Tucumán 1882 - Buenos Aires 1957) exchanged between 1931 and 1933 as regards the prestigious Guggenheim Fellowship granted to the rosarino architect and the consequent travel to the United States, a meridian fact in his intellectual itinerary. So, we intend to interrogate a writing practice along with his ideological interventions through the autobiographical continent (Antières y Dabbadie, 2019) or laboratory of ideas (Maíz, 2018) that conforms this selection of papers belonging to a major collection of unpublished letters (1925-1955). To say on other terms, we intend to map the interaction of individual matters (which was the architect's purpose after the Fellowship? which were the changes in his intellectual horizon? which thoughts were put into movement in his professional project during the American travel?) within a wider context where the leading question was the search for an American architecture, emancipated and with "Eurindica" source.

Keywords: Epistolary, Angel Guido, Ricardo Rojas, Guggenheim Fellowship, “Eurindica” architecture.

\section{Introducción}

Un maestro y su discípulo, un intelectual de fuste y un joven y pujante rosarino sostienen una relación epistolar durante tres décadas. Nos referimos al escritor y político Ricardo Rojas (San Miguel de Tucumán, 1882- Buenos Aires, 1957) y al arquitecto, ingeniero y urbanista Ángel Guido (Rosario, 1896-1960). Los une la amistad, aunque también la pasión por Eurindia, un modo de entender el arte y la arquitectura que hace de la fusión entre el elemento europeo y el legado indígena, su razón de ser y su horizonte de expectativa (Antequera, 2017).

Estos intelectuales se encuentran asimismo enlazados por varios proyectos en común. En efecto, conviene recordar solo dos sumamente importantes: en la década del veinte del siglo pasado, Guido fue el mentor de la morada de Rojas utilizando un lenguaje arquitectónico que la crítica bautizó como neocolonial ${ }^{1}$, memoria y nostalgia de la raíz hispanoamericana (Petrina, 2008); de igual modo, la puesta en escena de la tragedia Ollantay, reescritura de Rojas del drama quechua, lo tuvo a Guido como diseñador de la escenografía al promediar la década del treinta ${ }^{2}$. Sin embargo, la experiencia de un vínculo epistolar frondoso y profundo, sostenido desde 1925 a 1955, rubrica los pliegues de esa amistad, los derroteros de una trabazón profesional y la coincidencia en un modo de leer las coordenadas artísticas de su tiempo y de proyectar un arte de raigambre americana.

Una concatenación de piezas epistolares de las que solo tenemos las enviadas por Guido, gracias a la sensibilidad patrimonialista (Antelo, 2001) de Rojas, se presenta como una empresa sostenida durante tres décadas en donde afloran diversos tópicos: la preocupación por instaurar a nivel continental un arte americanista de entretela euríndica, la vinculación con otros

\footnotetext{
${ }^{1}$ El neocolonial es el primer movimiento estético-arquitectónico que elabora sus pautas a partir de una búsqueda de independencia estilística. Está conformado por diferentes inflexiones que van del neoindigenismo, la fusión hispanoindígena -que es la propuesta por Guido-, las acepciones ligadas al neoplateresco, el neoárabe y las vertientes hispanofilias, entre otras. Sugerimos consultar Aracy (1994); Gutman (1986); Gutiérrez (1984; 2018); Gutiérrez, Gutiérrez Viñuales, Gutman, Pérez Escolano y Weschsler (1995); Petrina (1992; 2006; 2008); Nicolini (1984). "Esta corriente de fuerte exaltación indigenista y americanista tendrá un claro reflejo en el mundo del arte, con manifestaciones de especial importancia en la música y la plástica, donde a la par que la expresión de una estética propia, se explorará la formulación de escuelas nacionales" (Petrina, 2008, pp.108- 155).

2 Algunas de las misivas desde EEUU del año 1933 comienzan a discurrir en torno a "Ollantay".
} 
intelectuales, los libros intercambiados, y por supuesto, las aspiraciones en común. En este sentido, la obtención de la prestigiosa beca Guggenheim por parte de Guido, gracias a las gestiones de Rojas, deja huellas en el epistolario.

Este corpus de correspondencias, salpicado de referencias a la cotidianeidad (Peluffo y Maíz, 2018, p.137) o atravesado por una ristra de detalles nimios de la vida cotidiana, contiene reliquias autobiográficas (Aurell, 2004) de un sujeto epistolar que, pulsando por encontrar su lugar en cierto contexto de producción intelectual, refrenda en cada carta su ideario. Las misivas, al ritmo de la vida, van acompasando entonces las vicisitudes en la obtención de dicha beca pero también dejan lugar -en los intersticios- para bordar una suerte de autobiografía ceñida a un corte temporal acotado, que se va construyendo al calor de ese trocar de correspondencia.

La búsqueda de legitimación, tan cara a intelectuales jóvenes, pujantes y rosarinos como Guido $^{3}$, incluía el forjar "las credenciales norteamericanas", según sus propias palabras, es decir, el trabar cierto prestigio profesional en el país del norte que fuera un envión para su prédica nacionalista $\mathrm{o}$, dicho en otros términos, para ganar esa pulseada por instaurar a nivel continental el pensamiento americanista de Rojas que hacía de la fusión del legado europeo y el sustrato indígena su impulso y motivación.

En particular, esta comunicación busca atender a la correspondencia que Guido y Rojas trocaron en un ininterrumpido periodo de tres años entre 1931 y 1933, en torno al hecho meridiano que significó, para el itinerario intelectual del arquitecto rosarino, el obtener la prestigiosa beca Guggenheim. Aunque intentamos recomponer ese diálogo a dos voces de la correspondencia epistolar, solo contamos con las cartas que Guido enviara a su maestro, por el afán archivístico del fundador de la primera cátedra de literatura argentina ya que las respuestas de Rojas se perdieron. Se trata entonces de interrogar una práctica de escritura junto a sus intervenciones ideológicas, a través de ese continente autobiográfico (Antières y Dabbadie, 2019, p.53) o laboratorio de ideas (Maíz, 2018, p.258) que conforma esta selección de cartas. Para decirlo en otros términos, procuramos cartografiar la articulación de lo individual -qué buscaba el arquitecto con la obtención de la beca, qué cambió en su horizonte intelectual, cuáles son los resortes que se mueven en su proyección profesional con el viaje a EEUU- con un plafón más abarcativo donde la pregunta por un arte americano emancipado se constituía en rectora. Estos son -sin más- los interrogantes que guían esta hoja de ruta.

De algún modo, la apuesta es entonces hacer circular el objeto cultural carta -en este caso concreto estas valiosas cartas inéditas- por otras redes: proponemos leer la obra de Guido como una constelación de textualidades, que incluye sus escritos programáticos, sus intervenciones artísticas y arquitectónicas junto a estos materiales de archivo para, de este modo, ampliar las bases de lo que se entiende por la obra de Ángel Guido. Esta investigación se apoya, como esbozamos más arriba, en el análisis más amplio de un corpus inédito conformado en su totalidad por 77 piezas epistolares, pertenecientes al rico acervo documental del Instituto de investigaciones del Museo Casa Ricardo Rojas. Son únicas en su especie puesto que no se hallan en otros repositorios ni archivos personales cartas que permitan reconstruir vinculaciones similares de este intelectual rosarino. De este conjunto epistolar, hemos seleccionados las piezas correspondientes al período 1931- $1933^{4}$ puesto que, aunque la beca se efectivizó a partir del 15

\footnotetext{
${ }^{3}$ Tal es el caso también de otro personaje al que le hemos dedicado varios estudios (Antequera, 2010; 2018; 2019): nos referimos a Alcides Greca, quien desenvolvió su labor como escritor, cineasta, jurisconsulto y docente universitario en la ciudad de Rosario.

${ }^{4}$ Las piezas que comprenden el lapso 1931-1933 son en total 23. Este corpus incluye cartas, tarjetas postales, tarjetas navideñas (Fig. 3), esquelas y cartas acompañadas por croquis.
} 
de octubre de 1932, pulsaba desde el deseo y desde el epistolario con cierta antelación y se proyectó en la vida del arquitecto como un momento trascendente para su ulterior desempeño intelectual.

\section{La beca Guggenheim o un rosarino en busca de credenciales norteamericanas}

Mar del Plata. Verano de 1932. Playa, sol y buenas noticias. Ángel Guido recibe el año con una excelente y ansiada novedad: ha obtenido una beca de la prestigiosa Simon Guggenheim Memorial Fundation para realizar investigaciones sobre arte y arquitectura en los Estados Unidos. El 25 de enero de ese año deja constancia epistolar de este hecho y le anuncia a su maestro y referente intelectual Ricardo Rojas que su inminente viaje está a punto de concretarse. Desde sus vacaciones en la perla del Atlántico, escribe una carta llena de júbilo:

El domingo pasado Csil me anunció verbalmente mi triunfo referente a la beca Guggenheim. Ya podrá imaginarse mi satisfacción y mi regocijo, pues, como Ud. bien sabe el camino más certero para la eficacia de mi propaganda americanista en arquitectura moderna está, en estos momentos, en obtener credencial norteamericana.

Estoy seguro que a mi vuelta me será sencillo salir airoso en cualquier polémica o ponencia proselitista en la universidad, congreso o públicamente, aunque repita los mismos conceptos de hoy. En efecto, ya anticipo de qué estarán llenas mis maletas de vuelta: justificaciones más anchas para mi fervor americanista; puntales nuevos para mi fe en su Eurindia; desbrozamiento y más certera precisión de mi 'criollismo mágico', que tanto me preocupa en estos momentos.

Ya podrá medir entonces, querido y admirado amigo, mi entusiasmo y también todo cuanto agradezco a su excesiva bondad para conmigo y al interés tomado en este asunto donde tengo la íntima satisfacción de saber que es a Ud. a quien debo mi éxito. Muchas pero muchas gracias, querido amigo, y reciba por hoy el cálido aprecio cada vez mayor de quien mucho lo admira. [Cursivas nuestras] (Guido, carta, enero 25, 1932)

No es tiempo de pensar en dificultades cuando todo es alegría para Guido. Pero para encuadrar el relato de aquellos días estivales de 1932 conviene establecer algunas precisiones. El viaje a Norteamérica entrañaba para Guido un fuerte anhelo cuyo legado implicaría, además de insuflar su fe americanista, un incremento sensible de su prestigio profesional, razón por la cual se robustecerían con renovados bríos sus argumentos. A fin de cuentas, la beca supondría defensas más incisivas de su credo y mayor profundización en dichos postulados, así como también nuevas preguntas. Ahora bien, ¿por qué Guido jalona las misivas haciendo referencia a estas necesidades intelectuales? ¿Por qué las cartas portan estos anhelos?

A la sazón, desde comienzos de la década del veinte, Guido venía librando enjundiosas batallas en torno a pensar un arte americano verdaderamente emancipado (Antequera, 2017). En rigor, desde la cátedra universitaria en la Universidad Nacional del Litoral venía realizando una defensa acérrima del americanismo ${ }^{5}$; asimismo, mediante la escritura de algunos libros como

${ }^{5}$ Con una claridad meridiana en sus objetivos, Guido hace escuela desde la cátedra universitaria. Como le comenta a Rojas en una misiva sin fecha: "Con gran satisfacción le envío recorte de 'La Nación' respecto al trabajo con el cual uno de mis discípulos obtuviera el primer premio de la Institución Mitre. La arquitectura moderna 'criolla' ha 
Fusión hispanoindígena en la arquitectura colonial (1925), Orientación espiritual de la arquitectura en América (1927), Arqueología y estética de la arquitectura criolla (1932) y de múltiples artículos, sentaba su posición ideológica; de igual modo sostenía una militancia incólume desde la práctica proyectual concreta: la mansión Fracassi (1925) y la casa de Rojas (1927, hoy Museo Casa Ricardo Rojas), por citar solo dos, ya eran parte de sendos paisajes urbanos y operaban como faros en la ciudad de Rosario, la primera, y en Buenos Aires, la segunda (Antequera, 2015; 2017).

Se podría pensar también que otro gesto emancipatorio y audaz fue la construcción de un oponente que a las claras era el arquitecto más importante del momento: una de sus intervenciones más virulentas fue una diatriba contra Le Corbusier, su enemigo intelectual, en el Tercer Congreso Panamericano de Arquitectos (celebrado en Buenos Aires entre el 1 y el 10 de julio de 1927), que luego devino en el libro La machinolatrie de Le Corbusier (1930), donde Guido con vehemencia criticó la ecuación arquitectura como sinónimo exclusivo de utilidad.

Conviene reparar ahora que la crítica tanto al eclecticismo y a las vanguardias, como su oposición a la hegemonía francesa se explican por la aversión al caos arquitectónico que ve en las ciudades, fundamentalmente en las ciudades-puerto (Buenos Aires, Rosario), aunque también en otros centros urbanos ${ }^{6}$. Para superar este problema, y otro inextricablemente unido, nos referimos a la dicotomía tradición/modernidad, Guido propulsa la búsqueda de la unidad arquitectónica en la diversidad, cuestión que claramente se puede observar al postular la fusión de lo indígena con lo hispano como articulación superadora. Expliquémonos mejor: esta suerte de conciliación de elementos disímiles vía Wölfflin ${ }^{7}$, presente a lo largo de sus textos e intervenciones, no desdice de lo moderno, puesto en tensión en las primeras décadas del siglo $\mathrm{XX}$, sino que, muy por el contrario, lo presupone. En otros términos, podríamos esbozar que Guido intentaba ser moderno y nacionalista a la vez: sin desdeñar de la tecnología y sus avances, bregó por articular un pasado indígena y un legado hispánico. Sin embargo, esta arquitectura americanista representada por Guido (pero también con diversas claves por Martín Noel, Héctor Greslebin y otros) enfrentó deslegitimación, desprestigio y una crítica mordaz: desde el arquitecto Alejandro Christophersen a la Revista Martín Fierro -dirigida por Evar Méndez y propulsada por Jorge Luis Borges, Oliverio Girondo y Alberto Prebisch-, es decir, desde el eclecticismo a la vanguardia denostaban esta estética fusional por ornamental.

El proyecto de expansión de su credo americanista estaba ya en el germen mismo de la tarea iniciada con Rojas unos años antes: aunados por la búsqueda de dirimir lo nacional y lo americano a través del arte, Rojas y Guido pensaban que no solo resultaba necesario sino también perentorio el refundar el arte en nuevas claves ideológicas. Razón por la cual, modelan esta modernidad antimoderna (Antelo, 2008, p.20), un constructo discursivo que hunde sus raíces en la pregunta por la identidad americana basándose en un arte que apela a un legado indígena -más

obtenido los dos primeros premios, pues, el segundo lo obtuvo otro alumno que fuera mío con un trabajo en estilo colonial. Como podrá Ud. deducir, estoy recogiendo ya los frutos de mi tesonero esfuerzo en la cátedra, por rehabilitar nuestro acervo criollo, de acuerdo a su siempre poco admirada 'Eurindia' y a su recuerdo de maestro" (Guido, carta, s/d).

${ }^{6}$ En su labor como urbanista, en las ciudades de Tucumán y Salta Guido proponía ordenar el caos arquitectónico desde el estilo neocolonial en su vertiente californiana, una suerte de argentinización desde el californian style.

${ }^{7}$ Muchos son los textos en donde Guido manifiesta abiertamente su adscripción al pensamiento de Heinrich Wöllflin. Por ejemplo: Orientación espiritual de la arquitectura en América (1927a); La arquitectura hispanoamericana a través de Wöllflin (1927b); Arqueología y estética de la arquitectura criolla (1932); Concepto moderno de la historia del arte (1935), por citar algunos. 
precisamente incaico en el caso de Guido- y de este modo, refunda sus bases. Este es el motivo por el cual las viviendas que Guido proyectó tienen ornamentación fusional entre lo europeo y lo indígena, donde cada detalle tiene una significación que remite a este proceso.

Para Guido y para las vertientes neocoloniales, el peligro lo constituían entonces las arquitecturas exógenas, caóticas y extranjerizantes que pugnaban por imponerse en el escenario latinoamericano. Es así como el ornamento es entronizado como vehículo y catalizador de la memoria. En rigor, podríamos resumir que desde el punto de vista arquitectónico, con la anatematización de la producción arquitectónica ecléctica de raíz europea como expresión de una sociedad que perdió su memoria, se produjo el surgimiento del movimiento neocolonial como forma de reencontrarla o, mejor aún, de refundarla apelando a un pasado indígena refuncionalizado.

A modo de horizonte de expectativa y de intento emancipatorio en el arte y en la arquitectura, Guido $(1925 ; 1927 a ; 1927 b)$ postuló que el proceso fusional euríndico acaecido en los siglos XVII y XVIII en las tierras de Arequipa (Perú) constituía un epifenómeno imposible de negar: la fusión operó combinando lo particular incaico, propio de esas lugarizaciones, con lo venido del otro continente, lo español. En tanto articuladora de dos elementos, Eurindia ${ }^{8}$, a la sazón ese entramado que explicaría el proceso transculturador, implicaba no solo un modo de entender la historia sino también de proyectar el presente en un aquí y ahora. Pero no nos adelantemos.

\section{Epistolaridad y deseo}

Volvamos a la misiva. El arquitecto rosarino apunta en esta carta citada más arriba que Rojas tuvo mucho que ver con la obtención de esta beca que le permitirá -y he aquí su ilusiónconstruir nuevas herramientas teórico-discursivas para defender la doctrina euríndica a capa y espada. Un adverbio presente en esta misiva, nos referimos al término verbalmente, delata que sin embargo el arquitecto se anotició de los resultados con antelación, de manera informal, solo posible por cierta cercanía o familiaridad entre el comité evaluador y su mentor, Rojas.

Conviene reparar entonces en que Guido fue nombrado por un comité de la beca desde y para la Argentina. En efecto, a partir de que la fundación estadounidense dispusiera la inclusión de Latinoamérica en este reconocimiento que originariamente solo circunscribía a EEUU, se establecieron comités de selección específicos para cada país: así, primero se comenzó a galardonar en México (1930), luego en Argentina, Chile y Cuba (1931) y desde 1932 también en Puerto Rico.

Ángel Guido fue el primer argentino en obtener este premio en su área de investigación: el campo de estudio de la arquitectura, el planeamiento y el diseño, perteneciente a la categoría Humanidades. Ese mismo año (1932), los otros profesionales en obtener este reconocimiento fueron el arquitecto chileno pionero en arquitectura hospitalaria Fernando Devilat Rocca (19061994) y el neoyorquino Lewis Mumford (1895-1990), célebre por sus concepciones sobre la ciudad jardín, entre otros notables aportes realizados.

Según se puede verificar en los archivos de la fundación estadounidense, la Argentina tuvo varios becarios ese año en diversas ramas del saber. Nos referimos al ingeniero del transporte Nicanor Alurralde (1898-1986), otro rosarino, a quien le debemos la construcción de

${ }^{8}$ Rojas había acuñado este nombre en un libro homónimo de 1924. 
importantes ramales ferroviarios (postulado por la disciplina Ingeniería); así como también el ictiólogo Tomás Leandro Marini (1902-1984) en la categoría Biología y Ecología y en el campo de los estudios sobre Literatura americana, obtuvo una beca quien fuera el fundador y director de la revista Síntesis, el ensayista Julio Fingerit (1901-1979). Antes de 1932, entre los argentinos que habían obtenido esta distinción podemos mencionar al escritor y fundador de la revista Inicial, Homero Mario Guglielmini (1903-1968), en la categoría Filosofía; al entrerriano Salomón Horovitz (1897-1978) en la disciplina Biología molecular y celular; y también podemos señalar en Economía, a Carlos García Mata (1905-1982), quien estudiara las causas de las fluctuaciones económicas. Estos tres fueron galardonados en 1931, la primera ocasión en que se dispuso otorgar este premio a profesionales, artistas e intelectuales argentinos. Guido se inserta así en esta serie de argentinos pujantes y prestigiosos.

Gracias a esta beca de intercambio, el inquieto arquitecto pudo viajar hacia EEUU donde investigó sus temas de interés americanista: hizo base en Los Ángeles -el remitente de sus cartas es 614 So, Gramercy Pl. (Fig. 4)- pero visitó otros sitios como Nueva York y Taxco (México), donde conoció personalmente a Diego Rivera y David Alfaro Siqueiros ${ }^{9}$ (Gibson, 1974, p.46).

El viaje se desarrolló a partir del 15 de octubre de 1932 y fueron ocho los meses de intensa pesquisa, visitas a bibliotecas, reuniones con intelectuales y dictado de conferencias y cursos. Estuvo acompañado por su esposa, la bella actriz uruguaya Bertha Eirin ${ }^{10}$, y sus tres hijas: la futura escritora Beatriz Guido (1922-1988), Bertha (alias "Tata") y María Esther (apodada "Beba"). Nos cuenta Guido: "Mi señora se ha aclimatado y mis nenas ya hablan (las dos mayores) inglés. Mis nenas han asimilado admirablemente esta nueva vida. Bertha también ya se ha aclimatado" (Guido, carta, mayo 17, 1933).

Al trote del deseo, estas escrituras ordinarias (Fabre, 1993) que conforman las cartas, es decir, estos usos de lo escrito definidos esencialmente como no literarios, domésticos, profesionales y personales (Antières, 2019, p.75) rezuman a contraluz ciertas estrategias de visibilidad que el arquitecto fue cimentando en esta experiencia viajera. Guido buscaba posicionarse y, para decirlo brevemente, constituirse en una voz autorizada en el mundo de la arquitectura. La ida a EEUU mediante la beca vendría a garantizar entonces no solo un pasaje a una escena más internacional del joven arquitecto sino lo que más le interesaba: la cimentación de una posición de enunciación, la construcción de una figura de intelectual prestigioso y militante del nacionalismo en arquitectura, esto es, ser un digno discípulo de Rojas. Si Rojas, unos años antes, en su Silabario a la decoración americana (1930) lo había bautizado como el arquitecto de Eurindia ${ }^{11}$, Guido hacía todo lo posible para encarnar este mote: es su obra, que por cierto dista mucho de la improvisación, la que a las claras hablará por el arquitecto.

\footnotetext{
${ }^{9}$ Quedarán para ulteriores trabajos los vínculos entre Guido y el muralismo mexicano.

${ }^{10}$ Para una caracterización de Bertha Eirin, esposa de Ángel Guido, sugerimos consultar el volumen titulado Una madre de Beatriz Guido, publicado por Emecé en 1973. Dicho libro compila pareceres de diversas personalidades que conocieron a Bertha, algunas cartas de juventud a su entonces novio Ángel Guido junto a pinceladas biográficas de Beatriz. También reconstruye literariamente en una suerte de genealogía prestigiosa y trágica, los antepasados uruguayos de su madre. En este corpus de correspondencia, el núcleo familiar de Guido no está tan presente como sí aparece, a modo de telón de fondo, en el vinculado a la construcción de la casa de Ricardo Rojas. Aquello que sí resulta digno de destacar es la contante presencia de la esposa de Rojas, Julieta Quinteros, en los saludos finales de innumerables piezas epistolares.

${ }^{11}$ Silabario... es, según Barovero (2018, p.40), "un corolario a la plástica de Eurindia. Rojas extendió la base inicial de su construcción de la argentinidad y la herencia indígena tomó una mayor sustentación que en sus libros anteriores en lo referente a la orientación y las posibilidades de un arte propio de los americanos. Se concentró en la investigación de aquel legado desde el punto de vista artístico, apoyándose en los estudios arqueológicos,
} 
Ahora bien, si repasamos el itinerario que coronó la obtención de la beca, podemos observar que fue un camino escarpado, y plagado de incertidumbres, ansiedades y deseos. Como se puede apreciar en las cartas, las idas y vueltas previas le pesaban a Guido y horadaban su ánimo y su temple. Por un lado, resulta innegable que el viaje se constituye en un fuerte anhelo: le ilusiona pensar que la experiencia le asegurará mayor repercusión entre intelectuales y artistas latinoamericanos y mayor prestigio para arremeter en las diatribas locales. Por otra parte, tengamos en cuenta que Guido promediaba los treinta años de edad y ya había ganado el concurso de emplazamiento del Monumento Nacional a la Bandera, ya había escrito una extensa lista de obras sobre estética e historia del arte y de la arquitectura, era profesor titular en la universidad pública, tenía en su haber la construcción de varias casas-manifiesto (Petrina, 2008) y había pergeñado los planes urbanísticos de algunas ciudades (entre ellas de su ciudad natal) pero aún así, el acceso a la beca no dependía tanto de su curriculum vitae -por cierto nada desdeñable- sino, más bien, estaba supeditado a los lazos y redes de sociabilidad; y es en este sentido que Rojas asume un papel protagónico, ciertamente tutelar.

Entre las cartas de Guido al fundador de Eurindia que se conservan, destaca otra, del 6 de enero de 1932, en la que se refleja su deseo volcado sobre el papel. Y en la que se palpa su ansiedad. Guido ha recabado una información importante y le escribe a Rojas:

He estado en esa [se refiere a Buenos Aires] con el Dr. Csil y le comenté su confusión de nombres que espero no sea un pronóstico poco feliz para mí. Referente a dicho asunto aún no hay resolución definitiva. Creo que son cuatro los candidatos que se encuentran en primer término, entre los cuales yo soy uno de ellos.

Pero como las becas son dos únicamente, mis probabilidades aún son problemáticas y su resultado definitivo se sabrá a principios de la semana próxima, antes del 15 .

En fin, ojalá tenga éxito y pueda desde los E. U. de N. A. trabajar con toda energía por Eurindia. Si la suerte me acompaña jamás olvidaré que le debo a Ud. a su gran bondad para conmigo, deuda moral que ojalá pueda yo pagarle algún día. (Guido, carta, enero 6, 1932)

Las cartas intercambiadas portan las huellas de este requerimiento explícito hacia Rojas y nos permiten distinguir nuevos visos, un entramado múltiple de esta relación asimétrica entre Rojas y Guido, el maestro y el discípulo. De esta manera, la epistolaridad se abre en abanico y nos puede aclarar algunas inquietudes: estos egodocumentos (Drekker, 2002; Grobe, 2015) en su dimensión dialogística (Saiz Cerreda, 2002; 2006) no revisten solamente el carácter de medio de comunicación de novedades librescas, acontecimientos del diario transcurrir o grandes gestas intelectuales, sino que constituyen un vehículo privilegiado para la intervención directa en la

etnográficos y prehistóricos. El Silabario es un estudio metódico de la estética de la iconografía americana que busca moldear una nueva moral cívica, un arte, una pedagogía, una política que redunde en beneficio de la conciliación racial, en la afirmación de pueblo común compuesto por todas las razas". En una carta sin fecha, Guido escribe a Rojas que será material de lectura obligatoria en los cursos de la Escuela de Dibujo de Rosario, de la cual él es el Regente y Dolores Dabat la directora: "No crea, querido amigo, que he olvidado su "Silabario". He iniciado en la Escuela Normal de esta, desde principio de este año, un Curso de "Composición Decorativa" en los cursos llamados "Vocacionales". He cumplido ya con la enseñanza de formas y ritmos, durante este primer semestre y comenzaré el segundo convirtiendo prácticamente aquellos conocimientos teóricos. El Silabario de la Decoración Americana será el libro de texto obligado. De este resultado práctico de mis alumnos pronto le daré noticias. Mi intención es la de conseguir la escuela más seria y eficaz en el sentido de preparar una posible industria decorativa nacional". 
gestión y obtención de un premio. Asimismo, esta carta nos revela que el arquitecto carga con el sentimiento de una deuda imposible de saldar. En resumidas cuentas, sabemos por el epistolario que Guido le pidió estratégicamente a Rojas su intercesión y que Rojas accedió y consiguió posicionar a su discípulo entre los cuatro candidatos con mayores chances de alcanzar ese galardón tan preciado. La obtención de este premio tuvo un carácter procesual que llevó varios meses hasta su concreción y es por medio de estos documentos epistolares como podemos cartografiar cuáles fueron la táctica y la estrategia.

A modo de ejemplo, entrada la primavera del año 1931, en una de las primeras misivas en donde el arquitecto discurre sobre este tema, Guido le expresa a Rojas su gratitud por otra gestión concreta:

Muchísimas gracias, querido amigo, por el gentil envío de la carta del Dr. Csil, que por lo visto a través de sus líneas, ya puedo ilusionarme un poco más respecto a la ampliación de mis trabajos euríndicos en el país que hoy tanto nos inquieta: E.U. de N.A.

Y si así fuera y lograra realizar dicho estudio, jamás olvidaré que la mayor parte del éxito la debo a su bondad y a la afectuosa y estimulante amistad que en todo momento me obsequia, a tal punto de inquietarme por el tema de no merecerla [Subrayado nuestro] (Guido, carta, septiembre 26, 1931). (Fig.1)

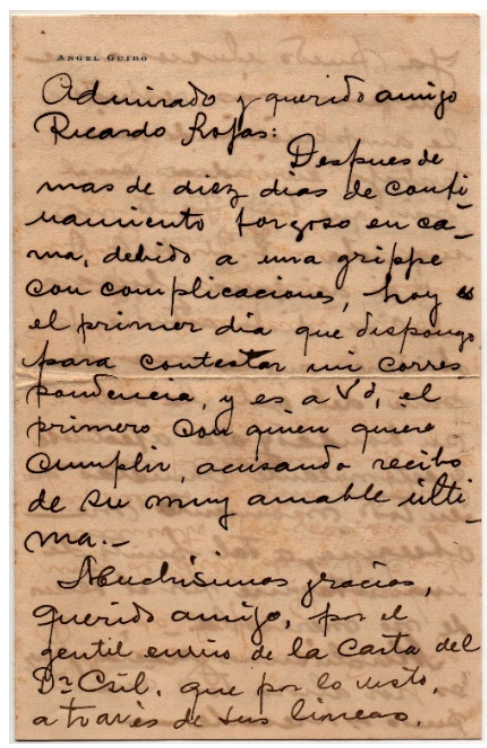

Fig. 1 Carta de Ángel Guido a Ricardo Rojas26 de septiembre de 1931. Casa Museo Ricardo Rojas.

Por el tenor del agradecimiento explícito y vigoroso ante las gestiones realizadas, podemos reponer sin más que Rojas hizo lobby por el arquitecto para la obtención de la misma. La relación con el Dr. Csil, de quien poco sabemos, no se perfila claramente pero parece adquirir una importancia considerable: fue el intermediario de la Simon Guggenheim Foundation en la Argentina, quien sacaba adelante las negociaciones y proporcionaba los datos sobre los progresos 


\section{María Florencia Antequera}

de las gestiones. Era, de alguna manera, el enlace pues detentaba la información sobre cómo avanzaban las chances del rosarino.

El capital simbólico de reconocimiento y consagración institucionalizados (Bourdieu, 1996, p.144) que portaba Rojas, le asignaba a sus apostillas y pareceres, a sus comentarios y juicios críticos, una función reguladora y amplificadora de las producciones que comentaba (Pasquaré, 2015) así como también una capacidad de influencia. Resulta claro entonces que una presentación y/o un comentario encomiástico de una figura tutelar de su talla dotaban al discípulo de cierta potencia enunciativa.

Durante varios meses, sin amilanarse ante la falta de novedades o ante la aparente oposición ideológica de alguno de los miembros del jurado (también por las cartas estamos al corriente de este dato), Guido sigue soñando con ese viaje al norte del continente que promete tantos y renovados bríos para su pasión americanista. Desde una habitación del Hotel Castelar, situado en la haussmaniana Avenida de Mayo y frecuentado en esa misma época por Federico García Lorca, Norah Lange, Oliverio Girondo, Alfonsina Storni, Jorge Luis Borges, entre otros artistas, Guido evoca sus incertidumbres y ansiedades y relata sus faenas en pos de la beca. Es así como en una carta sin fecha precisa, escribe (Fig. 2):

Parto ahora en el tren de mediodía. Aprovechando la mañana me entrevisté con el Doctor Csil, cuya entrevista se la transmito, recordando que Ud. deseaba conocer la marcha de mi asunto, actitud suya, repito, que me obliga a una deuda de bondad y amistad que no sé cuándo pagaré.

El Doctor Csil me expresó que aún no ha fallado el jurado y que recién lo hará, posiblemente, esta noche después de escuchar a dos candidatos más. Esta es la situación final aún de incertidumbre para mí, y muy especialmente por la circunstancia que entre los miembros del jurado hay quien niega al idealismo americanista tesoneramente. (Guido, carta, ca. 1932)

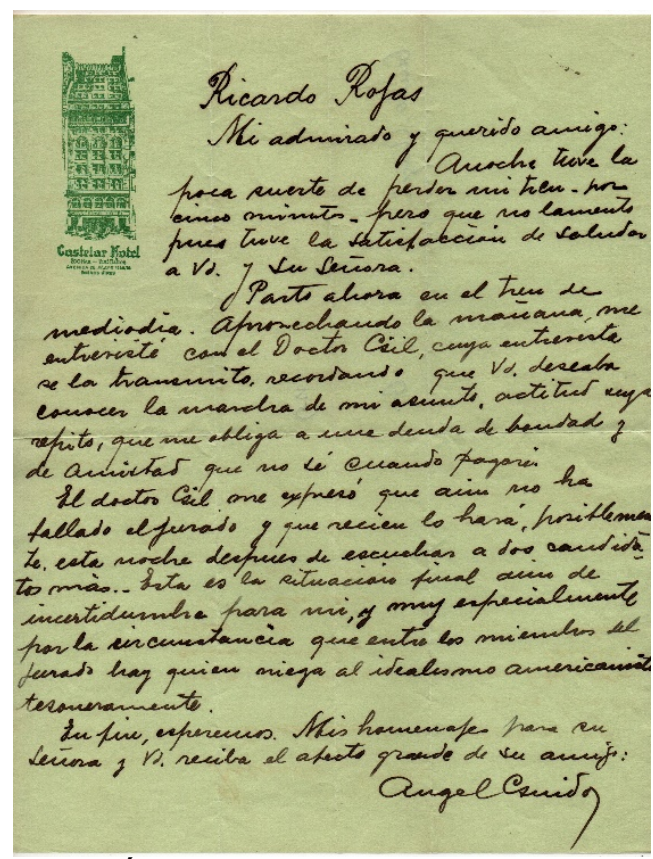

Fig. 2. Carta de Á. Guido a R. Rojas desde el Hotel Castelar 
A pesar de la ansiedad y de la incertidumbre reinantes, unos días después el jurado finalmente falló a su favor y en una misiva (ca. 1932) Guido relata que se encuentra en medio de los preparativos del viaje, no sin antes cumplimentar una tarea encomendada por la esposa de Rojas, Julieta Quinteros ${ }^{12}$. No olvidemos que la factura ad hoc del mobiliario de la casa de Rojas estuvo bajo los arbitrios de Guido:

Días atrás le envié la noticia que me transmitiera el Dr. Csil, referente a mi éxito en la beca Guggenheim, por lo cual ya estoy preparándome para mi viaje a los E. U. de N. A.

Hoy le envío los croquis de muebles que me había pedido su señora. Ruégale le trasmita mil perdones por la tardanza, un tanto excesiva, en remitírselos. Ruégale también que me disculpe el dibujo, hecho sin elementos de trabajo y en una incómoda mesita de cuarto de hotel.

No sé si serán de su agrado y si a su señora le satisfacen.

Yo creo que terminados con una estilización pronunciada de las cabezas del cóndor de Tihuanaco y con un policromado acertado, se puede lograr indianizarlos un paso más sin perder su carácter útil y cómodo.

En fin, si no le agradan, con toda franqueza, amigo Rojas, escríbame que le enviaré otro croquis. Recuerde que todo esto no es nada y menos aún que nada, al lado de los numerosos obsequios de amistad con que me ha colmado. (Guido, carta, ca. 1932)

En otra misiva expresa: "Desde Mar del Plata le envié algunos croquis de muebles, estilizando temas americanos, conjuntamente con una carta anunciándole mi éxito en la beca Guggenheim en la cual la agradecía su extraordinaria colaboración. ¿Recibió, querido amigo, todo eso?" (Guido, carta, abril 10, 1932). Las expresiones de gratitud, decíamos, proliferan en las cartas -gracias por la amistad, gracias por las gestiones realizadas, gracias por la atenta disponibilidad, gracias por la extraordinaria colaboración-; pero si hay un pensamiento que Guido no se permite es el de sentirse merecedor de la amistad de Rojas. A instancias de las cartas, vemos que esto le genera inquietud sin desasosiego.

En resumidas cuentas, la beca no implica solo el beneficio material sino, fundamentalmente, la obtención de una ganancia transformadora: la legitimación de su trabajo, aquello que da en llamar las credenciales norteamericanas. En última instancia, este viaje de estudios le ofrece al arquitecto de Eurindia un aventón hacia la consagración tan deseada. Conviene discurrir entonces en torno a los ribetes de la experiencia viajera para comprender la apuesta realizada.

\section{Luces y sombras de un viaje científico y profesional importador y exportador}

Queriendo practicar un cosmopolitismo de maletas (Schwartz, 2002), mecanismo a la vez importador y exportador, Guido viaja al norte del continente con una idea sumamente clara: desarrollar a nivel continental su credo americanista y traer en sus pupilas los rascacielos

\footnotetext{
${ }^{12}$ Guido se construye en las cartas como un hombre agradecido que retribuye con obras. La misma disponibilidad que se puede apreciar en el corpus de cartas vinculado con la construcción de la morada de Rojas (1925-1927), se puede ver en este conjunto epistolar.
} 
neoyorquinos que cavilados desvelos le producían. De este modo, podemos ver con claridad cómo la correspondencia opera como continente autobiográfico (Antières y Dabbadie, 2019, p.53) y como laboratorio de ideas (Maíz, 2018, p.258).

La experiencia traslaticia se enraíza así en un tipo de viaje científico y profesional: el viaje importador (Pasquaré, 2015, p.86) de conocimientos pero cabe destacar que también se constituirá -en primer lugar, desde su avidez lectora- en un viaje exportador. En efecto, estudiar y empaparse de lo nuevo en arquitectura, calibrar el estadio de la vertiente americanista en el país del norte, trabar vínculos con artistas mexicanos como David Alfaro Siqueiros y Diego Rivera se constituían en los impulsos importadores del periplo.

Sin embargo, el movimiento incluía también llevar la teoría euríndica y de este modo, ganar adeptos. Exportar la experiencia argentina de fusión euríndica era, sin lugar a dudas, lo más importante para Guido. Cargada de una seducción bifronte, la representación del viaje que Guido construye en las cartas incluye entonces el doble movimiento de exportación e importación.

De igual forma, el viaje también supuso algunas otras actividades académicas y científicas que son aludidas en las cartas:

Por acá, marchan muy bien mis trabajos. He recibido invitaciones para varias conferencias y posiblemente, se me solicite a principio del próximo mes, un curso semestral sobre arte hispanoamericano en una universidad. De llevarse a cabo, yo volvería recién en marzo del año próximo. (Guido, carta mayo 17, 1933)

Valiéndose de la estadía, la UNL lo nombró Delegado ante el Consejo y Senado de la Universidad de Nueva York donde se celebró un congreso sobre los desafíos de la institución universitaria, en el mes de diciembre de 1932. La conferencia que Guido presentó se tituló "Obligación de las universidades con respecto al orden social" 13 y giraba en torno a la formación integral (cultural) de los universitarios.

De igual modo, Guido aprovechó para visitar al arquitecto y académico norteamericano Rexford Newcomb (1886-1968) en Indiana (Rigotti, 2011, p.6), quien en 1916 había publicado el trabajo The Franciscan Mission Architecture of Alta California, texto pionero que varias décadas más tarde se propagaría en formato libro. Al igual que el rosarino, Newcomb tenía fruición por documentar las construcciones arquitectónicas: las fotografías tomadas dan cuenta de este deleite $^{14}$. En el caso de Guido, destacamos su pasión por las ilustraciones y el diseño gráfico como se puede observar en los textos que escribió en este periodo, que van acompañados por sus

${ }^{13}$ En esta comunicación y basándose en postulados de Ortega y Gasset, Guido caracteriza el problema central de su tiempo como "el imperio de la máquina" (Guido, 1937, pp.116-117) y del "técnico inculto" en contraposición a la cultura y la supremacía del espíritu. La solución que Guido proclama podría resumirse en la enseñanza de la cultura, mediante una Escuela de cultura (1937, p.119). Para tal fin, establece una nomenclatura de disciplinas que todo universitario debería cursar, a saber: a) Temas fundamentales sobre la evolución de la cultura (Historia); b) Temas fundamentales sobre la vida orgánica (Biología); c) Temas fundamentales sobre la vida social (Sociología); d) Temas fundamentales sobre el arte de los pueblos (Artes); e) Temas fundamentales sobre los sistemas económicos universales (Economía); f) Temas fundamentales sobre la actitud del hombre ante el universo (Filosofía). Esta propuesta dialoga con el resto de la producción del arquitecto.

${ }^{14}$ En veintitrés cajas de archivo de la colección documental Rexford Newcomb de la Universidad de Illinois at Urbana- Champaign donde este arquitecto fue docente por más de cuarenta años, se encuentran fotografías, piezas de su correspondencia privada y papeles personales así como también las publicaciones y libros. Lamentablemente, no hemos podido constatar empíricamente la presunción que albergábamos en torno a cartas intercambiadas entre Guido y Newcomb. 
dibujos sobre rascacielos (Guido, 1935) y en tantos otros a lo largo de su vida. Estos registros lo definen, por cierto, como el gran ilustrador que fue.

Asimismo, la Southern California University (1933) le otorgó el doctorado honoris causa en Bellas Artes, cumpliéndose así el lema del escudo universitario "Palmam qui meruit ferat" (Deja a quien merece honores lucirlos). Dice Guido a Rojas: "A mis anteriores antecedentes, he añadido aquí mi nuevo título de 'Doctor en Bellas Artes' (Doctor in Fine Arts) de la Universidad de Southern California, la más antigua universidad de California" (Guido, carta, agosto 19, 1933). Su estadía en esta institución además sirvió para estudiar la aplicación moderna del colonial misionero y mexicano. Más adelante en esa misma misiva, expone:

El próximo mes de septiembre parto para México para quedarme allí aproximadamente tres meses auspiciado por el Superior Gobierno de México, con el objeto de realizar un plan completo sobre 'Influencia india en la Arquitectura y Decoración (Arte en General) de los siglos XVII y XVIII'. Llevaré también el auspicio de esta Universidad de Southern California, en el sentido que se me publicarán en inglés mis investigaciones y se me obsequiará con cien ejemplares. Otro punto, referente a mi especialidad es que he sido el primer profesor de Historia del Arte (Universidad del Litoral) que he aplicado en mis cursos la modernísima teoría de Wölfflin, además la de Taine y Worringer. (Guido, carta, agosto 19, 1933)

El objetivo que Guido se imponía entonces en el país del norte por una parte incluía descifrar los grados de implementación de esta doctrina de cuño americanista a nivel continental $\mathrm{y}$, por otra, implicaba ampliar las bases de adhesión ${ }^{15}$, para este último fin servían también las conferencias y los cursos dictados. En rigor, estaba interesado no solo en los avances de la doctrina euríndica en las provincias argentinas sino en toda América, considerada como una pannación, que incluía a los países del norte del continente también. Como expresa la arquitecta Ana M. Rigotti (2011, p.6):

A diferencia de otros 'americanistas', Guido siempre se esforzó por integrar a Estados Unidos en esta construcción, una alianza 'entre el norte poderoso y la moneda espiritual del Sur' que considera consolidada durante la Segunda Guerra 'reeditando la hermandad de mitad del siglo XVIII' en un panamericanismo que propone sellar a través del arte.

Recordemos que proyecto arquitectónico, planificación urbanística e investigación constituyeron labores diversas pero abigarradas en su práctica profesional concreta. Como decíamos, el viaje lo encuentra al arquitecto con varias concreciones en su haber: sus obras arquitectónicas fusionales y sus reflexiones teóricas en torno a un arte emancipado, su amistad

\footnotetext{
${ }^{15}$ Sin embargo, esta voluntad multiplicadora, por llamarlo de algún modo, Guido la desarrolla desde sus inicios: prueba de esto es, entre otros tantos ejemplos, la línea editorial de la revista Arquitectura de la Sociedad Central de Arquitectos de Rosario que él dirigía. Guido no deja pasar la ocasión para infundir a su alrededor con tesón sus ideas euríndicas. Como muestra, el número 4 año 1 de la revista (1927) resulta sumamente elocuente: en la portada, diseño de Alfredo Guido; en el sumario: reflexión de Ángel Guido, fotografías de la morada neocolonial de Ángel Guido en calle Montevideo de la ciudad de Rosario, dibujos del frontispicio de la Iglesia de la Compañía en Arequipa y diseños varios (también de Á. Guido) y fragmento del texto Eurindia de Ricardo Rojas, acompañado por fotografías del pabellón de Polonia, proyectos de alumnos, actas de la Sociedad de Arquitectos y la nómina de los socios de dicha entidad.
} 
con Rojas, sus intervenciones públicas tanto en medios gráficos como en congresos y conferencias son las credenciales que él portará y mostrará en su viaje (como Sarmiento en su periplo a París llevó el Facundo ${ }^{16}$.

\section{Una querella simbólica por la nacionalidad}

Ahora bien, ¿cómo percibe Guido esta gramática americanista en el norte del continente, cómo evalúa su andadura, su desarrollo; él, que tiene clara conciencia de estar participando de la escritura de una nueva arquitectura para y por su tiempo? En primer término, podríamos decir que el contacto con otros exponentes del "movimiento colonial e indio modernizado", como expresa textualmente en las cartas, significó un espaldarazo para Guido, aunque también generó una suerte de sentimiento de amargura por ver que en Argentina no ocurría lo mismo "debido a nuestro proverbial derrotismo". En un fragmento de la misiva, con fecha del 18 de enero de 1933, le cuenta a Rojas que su trabajo en Norteamérica va sobre ruedas y que entre los intelectuales que él frecuenta arrecian los deseos de unidad e interacción:

Referente a mí, personalmente mis trabajos auspiciados por la John Simon Guggenheim Memorial Foundation marchan muy bien y estoy trabajando eficazmente en la hermosa ciudad de Los Ángeles.

El movimiento arquitectónico colonial e indio modernizado, por acá, en todo el Oeste, es sencillamente enorme. Amarga profundamente, que no se haya podido en la Argentina realizar una obra similar en arquitectura debido a nuestro proverbial derrotismo. Y lo más desagradable y doloroso es recordar que en nuestro país hay más razón -sea intelectual, espiritual o geográficamente- referente a la imposición de este estilo euríndico o criollo en la arquitectura moderna. De todo esto iré hablando en [el periódico] La prensa, pues, creo que haré una obra buena para la juventud artista, que se ha distraído demasiado en exitismos de segunda mano.

He conocido por acá a muchos artistas hispanoamericanos con tendencia americanista y muy especialmente mexicanos, y todos esperan conectarse entre sí y con el movimiento argentino.

Ahora bien, como su obra es conocida en toda América ¿no cree Ud. que sería eficaz, la publicación de una gran revista panamericana, editada en Buenos Aires bajo su dirección? Vaya esto como sugestión; pero creo yo, que falta un nexo de unión de todos los artistas americanos de orientación regionalista. Falta un maestro que haga sinfónico

\footnotetext{
${ }^{16}$ Este viaje que por cierto se iba extendiendo entre otros miembros de la intelectualidad americana. En rigor, en el período de entreguerras, el clásico viaje a Europa se irá superponiendo entre los profesionales e intelectuales hasta predominar el viaje a los EEUU (Cfr. Viñas, 2005, p.20). Guido no es el único arquitecto latinoamericano que viaja al país del norte para empaparse de los vientos modernos. En ese mismo año (1932), ideológicamente en la vereda de enfrente, dentro de un estilo sin ornamentos, con paramentos planos y grandes aventanamientos Corina Kavanagh enviaba al arquitecto Gregorio Sánchez a Nueva York al efecto de naturalizarlo con las operaciones de los rascacielos del flamante Rockefeller Center (Plotquin, 2018). Recordemos que Sánchez junto a Luis María de la Torre y Ernesto Lagos construyeron el emblemático Edificio Kavanagh, inaugurado a principios de 1936. Sugerimos consultar el texto de Silvio Plotquin titulado "Sánchez, Lagos y de la Torre: la iniciativa privada a la vanguardia de la interpretación normativa", en la Revista $A \& P 9$.
} 
este movimiento todavía disperso y nadie más que Ud. para ayudarnos. [Subrayado nuestro] (Guido, carta, enero 18, 1933)

Como vemos, Guido quiere que Rojas sea ese director de orquesta sinfónica de las diversas inflexiones del neocolonial para evitar de este modo, la dispersión. De alguna manera, también en este punto se puede vislumbrar que está bregando por ese pasaje de lo arquitectónico al archivo (Antequera, 2018), de lo arquitectónico a lo arquitextual de reconstrucción de la diseminación ${ }^{17}$ (Antelo, 2008-2009, p.13). Es decir, Guido también quiere ordenar la dispersión dentro de aquello que denomina movimiento colonial o artistas americanos de orientación regionalista. Guido intenta "una lectura radical de la antropomorfosis barroca para, a partir de allí, dar cuenta de la paradoja del ser nacional evaluado, al mismo tiempo, como local y occidental, es decir, como propio y como ajeno. Como lo otro apropiado y como lo propio enajenado" (Antelo, 2009, p.13). Y son las cartas, esos espacios de elucubración, esas arenas culturales al decir de Gorelik (2016) donde tienen lugar estos debates.

En segundo término, resulta necesario recordar que en las primeras décadas del siglo XX nos encontramos en plena controversia por el modo de traducir lo argentino y lo americano en el arte y la arquitectura, por encontrar un lenguaje propio o, en términos del filósofo e historiador Oscar Terán (2000, p.352), "dirimiendo en la Argentina una querella simbólica por la nacionalidad". Conviene entonces tener en cuenta la reverberación continental de esta inquietud.

Como ya expusimos en otro trabajo (Antequera, 2017) hacia 1910 Latinoamérica se vio arrumbada por una serie de epifenómenos que habrían de repercutir de manera determinante en el campo del pensamiento continental y nacional: si en el norte del continente se producía la revolución mexicana con reivindicaciones del olvidado y relegado esplendor precolombino; en el sur, la Argentina optaba en su Centenario por un modelo marcadamente eurocéntrico. Entonces, surgirán las primeras indagaciones sobre una identidad que el aluvión inmigratorio tornaba cambiante y aleatoria. Aquí es donde el prolífico Rojas interviene con su obra La restauración nacionalista (1909), reafirmando su tesitura con la posterior edición de Eurindia (1924).

El contexto propiciaba que diversos intelectuales pugnaran por darle dimensión americana al arte, la arquitectura, las letras, la filosofía. Partiendo de ideologías, prácticas y experiencias disyuntas, pensemos en ciertos intelectuales que contribuyeron al establecimiento de las bases de un pensamiento de auténtica dimensión americana: por ejemplo, recordemos a personalidades de la talla del mexicano José Vasconcelos (1882-1959) -promotor del movimiento muralista a partir de la década del veinte- quien con su célebre La raza cósmica (1925) destacaría que el mestizaje era el perentorio crisol superador de razas; o bien el peruano José Carlos Mariátegui (1894-1930) con sus Siete ensayos de interpretación de la realidad peruana (1928).

Argentina desempeñó un destacado rol en el panorama arquitectónico del período, aunque su participación -con ser cuantitativamente menor que la que le cupo a México o Perúsobresalió especialmente en el área teórica, donde los dos representantes principales del movimiento neocolonial, Martín Noel y Ángel Guido, ejercieron una influencia de relevancia continental (Petrina, 2008; Cicutti y Nicolini, 1998). Entre estos dos arquitectos, fue Guido quien

\footnotetext{
${ }^{17}$ Raúl Antelo tiene dos textos sumamente incisivos en donde discurre sobre diversos aspectos del pensamiento de Guido. Estos son: "Cerimonial y anacronismo: Ollantay" (2011). Disponible en: http://qorpus.paginas.ufsc.br/como-e/edicao-n-002/cerimonial-e-anacronismo-ollantay-raul-antelo/y de 2009, "Posautonomía: pasajes", Pasajes: Revista de pensamiento contemporáneo, n. 28: 11-20. Disponible en: http://roderic.uv.es/bitstream/handle/10550/46258/11-20.pdf?sequence=1\&isAllowed=y.
} 
mayor cantidad de textos escribió sobre estas preocupaciones que -huelga aclarar- no desdeñaban partir de programas modernos. Es decir, sus propuestas consideraban las premisas y necesidades del presente de la enunciación para la producción de una arquitectura actualizada y así atenta a las demandas crecientes, incluyendo los progresos técnicos pero utilizando un lenguaje que reconstruía un pasado precolombino.

Sin desdeñar la técnica y la tecnología, Guido prorrumpió con una prédica fusional cuya modernidad antimoderna, al decir de Raúl Antelo (2017), instalaría en el escenario la tan mentada emancipación artística. En esta línea de pensamiento reivindicatorio de lo americano es donde se reescribirá la arquitectura, pero también la historia del arte, bajo los arbitrios de Ángel Guido.

\section{Nuevos horizontes para la Eurindia viva: entre el californian style y las catedrales del siglo $\mathrm{XX}$, los rascacielos}

Ese gusto epistolar, forma de contacto habitual entre los dos amigos, revela que desde el norte, Guido expone sus inquietudes, aquello que en definitivas le quita el sosiego. Entre el ajetreo y la aceleración que percibe en la vida en EEUU, Guido busca un reducto de paz y en unas líneas expone que el país del norte es contradictorio y extraordinario:

Siempre he deseado encontrar un momento silencioso y apropiado para escribirle, en medio de este ruidoso vivir de las ciudades americanas. No podía pagar su última gentileza para conmigo con líneas telegráficas. Mas ese momento es difícil encontrarlo y contagiado de este agitador andar le envío estas líneas apresuradas pese a mi deseo de desubicarme de este clima de constante aceleración.

De cualquier modo, ojalá interprete Ud., que si al salir de la Argentina he dejado un gran afecto intelectual y de amistad es seguramente Ud., mi gran amigo y maestro.

Mucho desearía transmitirle mis impresiones, referente a este extraordinario país, extraordinario siempre, sea en la virtud como en los defectos. Pero sería muy largo, y además, algo de estas impresiones mías aparecerán en La prensa. Solo cabe decirle que mi impresión general es la de un país enorme y contradictorio. (Guido, carta, enero 18, 1933) 

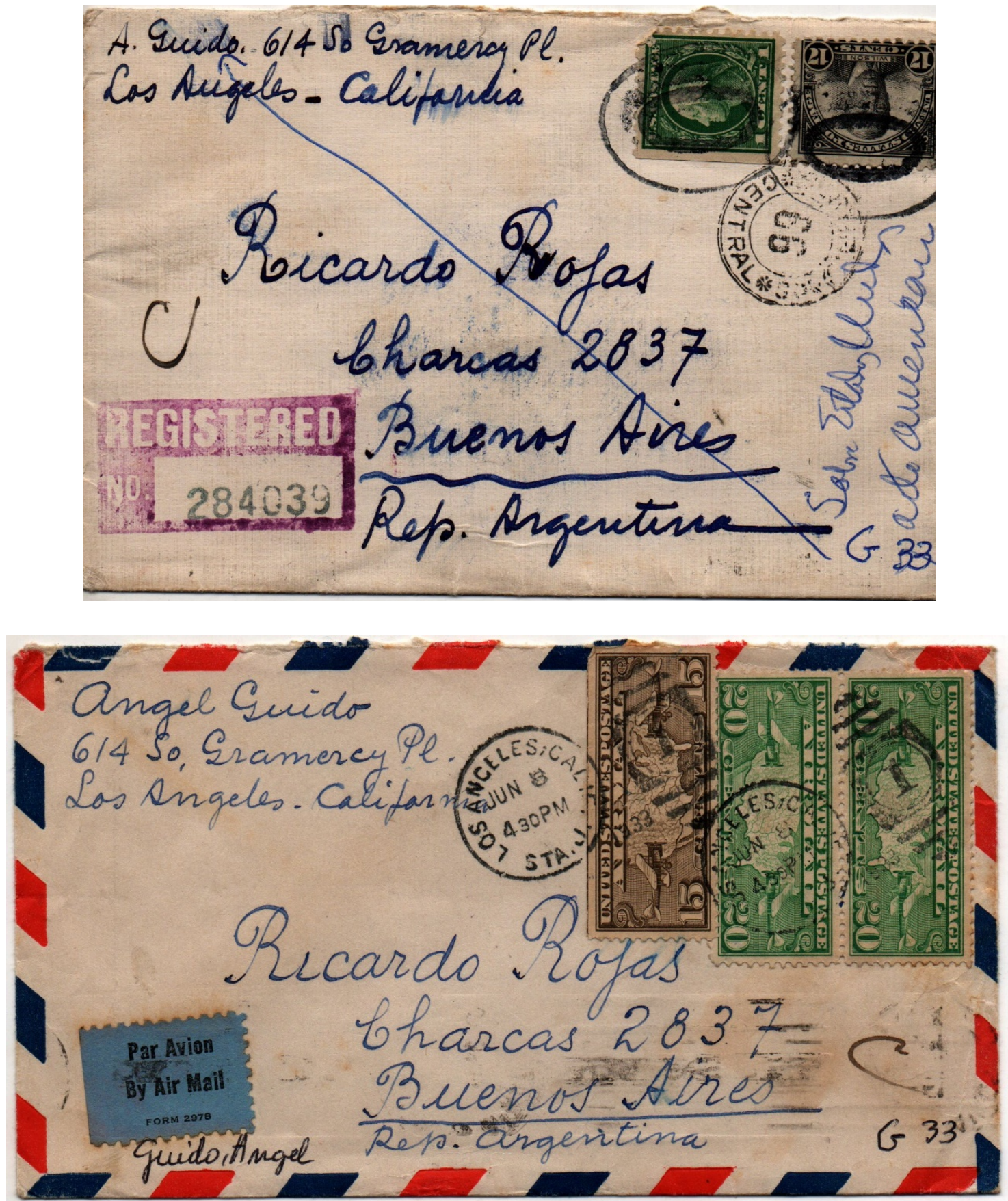

Fig. 4 y 5. Dos sobres con la dirección norteamericana de Guido, desde donde enviaba la correspondencia a su amigo R. Rojas: 614 So, Gramercy Pl. Los Ángeles. Nótese la dirección del destinatario: Charcas 2837, el hoy Museo Casa Ricardo Rojas.

Al sur de California, la ciudad de los Ángeles se le presentó a Guido como una posibilidad para literalmente abrir nuevos horizontes. Es así como por las cartas, nos anoticiamos 
que Guido experimentó en EEUU la fuerza del californian style ${ }^{18}$, por entonces de moda entre arquitectos de México y EEUU (Gossman, 1998), los cuales construían casas para las clases medias y altas. En resumidas cuentas, eran casas modernas vinculadas a los principios del confort y la tecnificación (Chiarello, 2015, p.186) con una estética que incorporaba el ornamento y estaba asociada a reminiscencias nacionalistas. Guido vio en estas construcciones su ideal de unión entre la técnica y la emoción americana, como expresó años antes en un escrito programático (Guido, 1930). Sin embargo, el rosarino también vislumbró en esta arquitectura aquello que algunos años más tarde conceptualizaría como "un nuevo espíritu antimaquinista" (Guido, 1940-1941, p.114).

Ahora bien, conviene apuntar que fue sintomáticamente a través del cine como se divulgó este estilo. En la región de California se desarrolló uno de los principales "polos de irradiación de nuevos códigos arquitectónicos, en gran parte debido a las posibilidades brindadas por la industria cinematográfica”, según expone la arquitecta Ana Chiarello (2015, p.187). Guido sintió ansias de conocer estos sitios y esta vertiente del neocolonial que se extendería por la península de Florida -mediante residencias particulares aunque también edificios públicos- y se publicitaría por sus estrechos vínculos con el cine:

El tipo llamado chalet californiano debe su nombre a una arquitectura doméstica surgida en la región de California, Estados Unidos, en las primeras décadas del siglo XX. Su difusión se produjo luego de la Primera Guerra Mundial por la prevalencia de la cultura norteamericana en todo el mundo, a través de revistas de divulgación masiva y revistas especializadas y sobre todo el cine. (Chiarello, 2015, p.187)

De igual modo, este nuevo gusto por lo hispano, consagrado definitivamente en las exposiciones de San Diego y de San Francisco de California en 1915, fue extendiéndose al Caribe todo y con énfasis en Puerto Rico dándose inicio a una corriente intelectual y artística que ha sido caratulada de Hispanofilia (Gutiérrez Viñuales, 2003, p.174). También denominada como mission style, esta arquitectura recuperaba para obras contemporáneas las líneas decorativas de las arquitecturas californianas de antaño (Gutiérrez Viñuales, 2003). Como vemos, entre fines del siglo XIX y principios del XX se desarrolló en esta zona

un tipo de arquitectura vinculada al repertorio formal hispánico, que habría de tener un particular impacto en la vivienda. California estaba vinculada al mundo cultural hispano, ya que había formado parte del territorio mexicano durante el período virreinal y no fue sino hasta el siglo XIX, y como consecuencia de la guerra entre México y Estados Unidos (1846-1848), que pasó a formar parte de este último. (Chiarello, 2015, p.187)

\footnotetext{
${ }^{18}$ Según el investigador mexicano Rafael F. Gossman (1998, pp.20-21), en el caso mexicano existen tres vertientes del neocolonial: "una que se origina durante el eclecticismo del porfiriato y que curiosamente será el símbolo con que los gobiernos posrevolucionarios imprimen validez al discurso modernizador: el neocolonial; otro que se origina en EEUU y llega a nuestro país desde la década de los veinte y que se populariza de manera casi paralela a la anterior: el spanish colonial revival; la tercera que generalmente se liga con el spanish colonial, y que modifica las características expresivas, así como los esquemas y distribución de los espacios: el neobarroco. Se crea así un nuevo modelo, que incorpora una serie de elementos expresivos de carácter ornamental, que hacen aceptables para la sociedad de su momento las aportaciones que el racional-funcionalismo introduce, dándose así la verdadera generalización de la modernidad en la ciudad y el país, dentro de un patrón ecléctico teñido de nostalgia y que de manera reiterada se asocia con el nacionalismo". Ver el libro completo, editado por Fondo de Cultura Económica y titulado La gran corriente ornamental del siglo XX. Una revisión de la arquitectura neocolonial en la ciudad de México (2007).
} 
Guido advirtió en esta proliferación de casas y edificios públicos, una vitalidad de la teoría euríndica. Sin embargo, resulta interesante destacar que la apropiación y el estudio del Mission style bascularon simultáneamente en el interés de Guido por los rascacielos vistos en Manhattan. Rigotti $(2011$, p.6) lo postula en estos términos:

Mientras [Guido] dictamina para el noroeste argentino la recuperación del funcionalismo real de las recovas, techos de tejas y muros blancos cuya rehabilitación moderna e inteligente síntesis en el Mission Style californiano destaca, para las ciudades cosmopolitas del litoral donde lo portuario impulsa la polifonía estética, el modelo evidente será Nueva York y sus rascacielos.

Cierto es que -más allá de sus expectativas con su viaje, es decir, robustecer sus argumentos para defender su fe euríndica y ensanchar su prestigio profesional- algo se mueve en su interior, algo del orden de la epifanía cuando contempla, maravillado, los rascacielos neoyorquinos: "He aquí, pues, finalmente, el espíritu de ese gigante que emerge de las ciudades americanas y que desde el avión se nos antojaban entidades vivas" (Guido, 1935, p.86). Un proceso que podríamos caracterizar como disyunto pero simultáneamente convergente es el que lo lleva a conceptualizar en obras ulteriores, por una parte, los rascacielos como las nuevas catedrales del siglo XX puesto que son "la expresión más ajustada a la era maquinista, comparable con las grandes catedrales del gótico" (Guido en Rigotti, 2011, p.6), y, por otra, paralelamente a destacar el californian style.

En efecto, si el proceso fusional que Guido defendía no hizo caso omiso de los avances técnicos y tecnológicos, tampoco se desligó de la coyuntura al anhelar un futuro anterior, una modernidad anclada en elementos precolombinos. Por el contrario, en este viaje entronizó el rascacielos como "espectáculo extraordinario de pujanza e impulso dinámico emergiendo temerario sobre la línea horizontal de la ciudad extendida" (Rigotti, 2011, p.6). El rascacielos, que para Guido "nació inspirado en un mito muy de nuestro tiempo: la máquina" (Guido, 1935, p.83), es "la obra de arquitectura más extraordinaria de nuestro tiempo" (Guido, 1935, p.86).

Una de sus preocupaciones centrales era el caos arquitectónico y urbanístico que veía en las ciudades argentinas, más aún en la ciudad puerto en la que había nacido. La reflexión euríndica -a fin de cuentas una reescritura del pasado incaico en confluencia con el legado europeo- fue impulsada desde diferentes aristas con suma perseverancia. Lo curioso del caso es que, como decíamos, son los rascacielos los que a su parecer, junto a las casas neocoloniales, constituyen la Eurindia viva. Varios son los textos que, tributarios de estas preocupaciones suscitadas por este viaje al norte del continente, son escritos a posteriori: "Ensayo sobre una biología del rascacielo" (1935), Catedrales y rascacielos (1936) y Redescubrimiento de América en el arte (1940).

En este último conceptualizó aquello que denominó Eurindia viva, la actual, la que se estaba concretando en su presente de enunciación. Como contrapartida, delineaba la Eurindia arqueológica, aquella tributaria del proceso transculturador acontecido en los siglos XVII y XVIII. Eurindia viva estaba presente en los gallardos rascacielos:

Eurindia viva finalmente es la actualísima, la que corresponde a las presentes y futuras generaciones de artistas jóvenes en América. Formarán, a buen seguro, las nuevas legiones de pioneers y bandeirantes, lanzados a la gran aventura de redescubrir 


\section{María Florencia Antequera}

hombres, bosques, montañas, pampas, desde el generoso valle mexicano y el caliente trópico yucateco hasta la frígida Patagonia argentina. Desde otro flanco, ya los americanos del norte han creado un ejemplo singular de esta Eurindia viva: los gallardos Rascacielos, que emergen del Manhattan con un gesto no europeo, por cierto. Y los mexicanos tienen también la Pintura mural y social, otro ejemplo magnífico de esta soñada Eurindia viva de América. Por esta causa dediqué a cada una de aquellas admirables realizaciones euríndicas, sendos trabajos insertos en esta obra. (Guido, 1940, p.13)

Esta estancia de pesquisa en el país del norte, decíamos, fue una ocasión propiciatoria para evaluar (y refrendar según surge de las cartas), desde un plafón más amplio, el arraigo de la doctrina euríndica a lo largo y a lo ancho del continente americano. El gesto -ampuloso y ambicioso a la vez- no desdice de una férrea perseverancia por estas temáticas que Guido forjó a lo largo de su vida. Resulta a las claras que esta experiencia fue profunda y enriquecedora para su carrera profesional: por cierto, en las cartas esboza sin titubeos que la razón primordial se relaciona con el trabar vínculos con varios artistas latinoamericanos y norteamericanos cuyos intereses giraban en torno al lenguaje arquitectónico neocolonial y a lo euríndico, que distaba mucho de ser una corriente de pensamiento homogénea y hegemónica pero que, sin embargo, disputaba ciertos espacios de visibilidad en el plano teórico y proyectual.

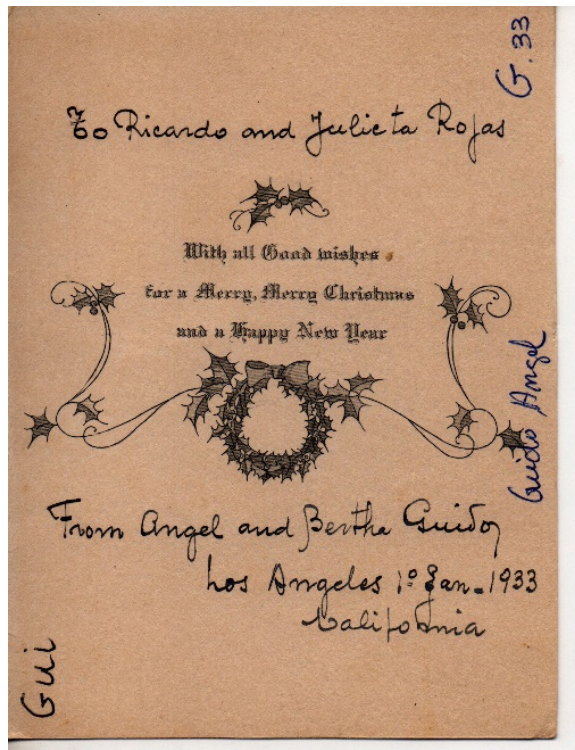

Fig. 3. Tarjeta navideña para Ricardo Rojas y Julieta Quinteros desde Los Ángeles. 1 de enero de 1933.

\section{Conclusiones}

El epistolario inédito de Ángel Guido a Ricardo Rojas constituye un material de gran valía puesto que sirve para auscultar los ritmos de los debates por el arte americanista de la primera mitad del siglo veinte y también porque delimita un vínculo de amistad entre dos exponentes de 
la intelectualidad argentina, vínculo que no ha sido suficientemente estudiado. El trabajo con este material inédito adquiere especial relevancia, no solo como observatorio de los mecanismos para la consagración de Guido como figura intelectual sino, quizás más importante, para profundizar en la evolución de sus ideas, la construcción de su itinerario académico, las transfiguraciones de su pensamiento y, en un contexto ampliado, un episodio de la vida cultural argentina en la primera mitad del siglo veinte.

Si la amistad se teje en este trocar de cartas durante el trienio 1931-1933, también a través de estos documentos se pueden vislumbrar los entresijos autobiográficos de un viaje que este arquitecto rosarino pulsa por construir: en busca de lo que hemos denominado credenciales norteamericanas, es decir, una legitimación en el exterior que permita revalidarse y reconocerse como una voz de autoridad en el origen, Guido emprende una experiencia viajera de importación y exportación de conocimientos, con la ambición de instaurar a nivel continental el ideario compartido con Rojas. Pero todo viaje entraña nuevos horizontes: no se es el mismo sujeto al emprender el periplo que a la vuelta del mismo. En efecto, Guido se fascina tanto con los rascacielos como con los chalets californianos porque viajó para calibrar el estado de Eurindia en el norte del continente y se encontró con la Eurindia viva, una fusión que estaba aconteciendo en el mismo presente de la enunciación.

Al realizar una cartografía por los temas incluidos en las misivas del período 1931-1933, podemos reconocer los intereses de Guido: en primer lugar, el arte y la arquitectura de cuño americanista; también, los proyectos artísticos que lo unían a Rojas, junto a impresiones motivadas en el país del norte, futuras publicaciones e intervenciones en la prensa y nimiedades del diario vivir. Esos fuertes anhelos por obtener la beca Guggenheim y viajar a EEUU hilvanan las misivas en el trienio estudiado; en fin, como vemos, nos remiten sin más al arte y la vida.

Al preguntarnos por la práctica de escritura epistolar que realiza Guido, junto a sus intervenciones ideológicas, a través de ese continente autobiográfico (Antières y Dabbadie, 2019, p.53) o laboratorio de ideas (Maíz, 2018, p.258) que conforma esta selección de cartas, procuramos cartografiar la juntura de un itinerario individual (su horizonte intelectual, su proyección profesional, sus anhelos) con un colofón más amplio que contenía la propuesta por un arte y una arquitectura emancipados.

Al ampliar los márgenes de lo que se entiende por obra de Ángel Guido, bregamos por incluir y poner en diálogo materiales heteróclitos para enriquecer la perspectiva: textos publicados, intervenciones culturales, obras arquitectónicas, cartas inéditas entre otras textualidades.

Las cartas muestran que el remitente, al abrir su intimidad, deja traslucir sus deseos y ansiedades y funciona como un cronista inquieto, un viajero singular, cuyas observaciones palpitan por materializarse en la letra: nuevos paisajes culturales y vicisitudes del diario vivir se manifiestan en la pluma del arquitecto. Este cosmopolitismo de maletas que Guido realiza, se encuadra dentro de una querella simbólica por la nacionalidad, dentro de una búsqueda mayor por emancipar al arte y la arquitectura. Pero, como sabemos, no hay búsqueda sin deseo y no hay viajero sin equipaje: en este caso, nos encontramos con un sujeto epistolar cuya pulsión por construir Eurindia implicaba no solo un modo de entender la historia sino también de proyectar el presente en un aquí y ahora. 


\section{Referencias bibliográficas}

\section{Sección epistolario}

Guido, Á. (26 de septiembre de 1931). [Carta para Ricardo Rojas]. Museo Casa Ricardo Rojas, Ciudad Autónoma de Buenos Aires.

. (6 de enero de 1932). [Carta para Ricardo Rojas]. MCRR, CABA. . (25 de enero de 1932). [Carta para Ricardo Rojas]. MCRR, CABA. . (10 de abril de 1932). [Carta para Ricardo Rojas]. MCRR, CABA. . (c. 1932). [Carta para Ricardo Rojas]. MCRR, CABA. . (c. 1932). [Carta para Ricardo Rojas]. MCRR, CABA. . (18 de enero de 1933). [Carta para Ricardo Rojas]. MCRR, CABA. . (17 de mayo de 1933). [Carta para Ricardo Rojas]. MCRR, CABA. . (1 de enero de 1933).[Tarjeta navideña para Ricardo Rojas y Julieta Quinteros]. MCRR, CABA.

\section{Fuentes}

Guido, Á. (1925). Fusión hispano-indígena en la arquitectura colonial. Rosario: La casa del libro.

. (1927a). Orientación espiritual de la arquitectura en América. Rosario: Talleres Gráficos La Tierra.

. (1927b). La arquitectura hispanoamericana a través de Wöllflin. Rosario: Cruz del Sur.

. (1930). Eurindia en la arquitectura americana. Santa Fe: Universidad Nacional de Litoral.

- (1935). Ensayo sobre una biología del rascacielo. Órgano oficial del Centro de estudiantes de la Facultad de Ciencias Matemáticas de la Universidad Nacional del Litoral, 8

. (1936). Catedrales y rascacielos. Buenos Aires: Ed. Colegio Libre de Estudios Superiores.

. (1936-1937). Obligación de las universidades con respecto al orden social. Órgano oficial del Centro de estudiantes de la Facultad de Ciencias Matemáticas de la Universidad Nacional del Litoral, 11.

. (1940). Redescubrimiento de América en el arte. Rosario: Universidad Nacional del Litoral.

. (1940-1941). Arquitectura del siglo XIX (Transcripción y resumen de curso dictado en el Colegio Libre de Estudios Superiores de Buenos Aires). Órgano oficial del Centro de estudiantes de la Facultad de Ciencias Matemáticas de la Universidad Nacional del Litoral, 16.

\section{Textos críticos}

Antelo, R. (2001). Política del archivo. Iberoamericana, LXVII(197), 709-720.

. (2008-2009). Posautonomía: pasajes. Pasajes, 28, 11-20.

- (2017). Ángel Guido, la fusión, el círculo. Cuadernos de Historia del arte de la

Universidad Nacional de Cuyo, 28, 99-158. 
Antequera, M. F. (2014-5). La residencia y casa de rentas Fracassi, una inflexión del neocolonial en la ciudad de Rosario. Res Gesta, 51, 189-198. . (2017). Un libro y una casa: Ángel Guido en la encrucijada euríndica. Cuadernos de Historia del arte de la Universidad Nacional de Cuyo, 28, 43-98. . (2018) El viaje iniciático. En Gutiérrez, R. (Comp.). El pensamiento americanista en tiempos de la Reforma Universitaria. Ricardo Rojas-Ángel Guido. Buenos Aires: CEDODAL y Fundación Bunge y Born.

Antières, P. (2019). La escritura obligada: Recuerdos de un gorrión o Confidencias de un presidiario. En Antières, P. La experiencia escrita. Estudios sobre la cultura escrita contemporánea (1871-1981). Buenos Aires: Ampersand.

Antières, P. y Dabbadie, D. (2019). Resistir la prisión a través de la autobiografía: Vera Figner y las prisiones zaristas. En Antières, P. La experiencia escrita. Estudios sobre la cultura escrita contemporánea (1871-1981). Buenos Aires: Ampersand.

Aurell, J. (2004). El texto histórico como relato autobiográfico. Actas III Congreso Internacional Historia a Debate. Santiago de Compostela.

Barovero, D. (2018). La mirada integradora: Eurindia. En Gutiérrez, R. (Comp.).El pensamiento americanista en tiempos de la Reforma Universitaria. Ricardo Rojas- Ángel Guido. Buenos Aires: CEDODAL.

Bourdieu, P. (1996). Cosas dichas. Barcelona: Gedisa.

Cicutti, B. y Nicolini, A. (1998). Ángel Guido, arquitecto de una época de transición. Cuadernos de Historia del Instituto de Arte Americano e Investigaciones Estéticas Mario J. Buschiazzo, 9, 8-58.

Chiarello, A. (2015). El tipo chalet californiano en la arquitectura doméstica del noroeste argentino. Tucumán y Salta, 1930-1950. Revista de Historia Americana y Argentina de la Universidad Nacional de Cuyo, 50(2), 185-214.

Fabre, D. (Dir.) (1993). Écritures ordinaires. París: POL/BPI- Centre Pompidou.

Drekker, R. (2002). Egodocuments and history: autobiographical writing in its social context since the Middle Ages. Hilversum: Verloren. 7-20.

Gibson, C. (1974). Cinematic Techniques in the Prose Fiction of Beatriz Guido. (Tesis doctoral) EEUU: Universidad de Michigan.

Gorelik, A. y Arêas Peixoto, F. (Comp.) (2016). Ciudades sudamericanas como arenas culturales artes y medios, barrios de élite y villas miseria, intelectuales y urbanistas: cómo ciudad y cultura se activan mutuamente. Buenos Aires: Siglo XXI.

Gossman, R. (1998). La gran corriente ornamental del siglo XX: una revisión de la arquitectura neocolonial en la ciudad de México. México DF: Universidad Iberoamericana.

Grobe, S. (2014). Cartas e correspondência ordinária como ego-documentos na análise lingüística. Revista LinguíStica Programa de Pós-Graduação em Linguística da Universidade Federal do Rio de Janeiro, 11(2), 22-41.

Gutiérrez Viñuales, R. (2003) El hispanismo como factor de mestizaje en el arte americano (1900-1930). En AAVV.Iberoamérica Mestiza. Encuentro de pueblos y culturas (pp. 167-185). Madrid, Sociedad Estatal para la Acción Cultural Exterior-SEACEX.

Gutman, M. (1988). Neocolonial: un tema olvidado. Anales del Instituto de arte americano e investigaciones estéticas Mario J. Buschiazzo, 5, 1-26.

Maíz, C. (2018). Modernidad, inconformismo y tensiones emocionales: El Epistolario inédito (1894-1936) de Miguel de Unamuno. Landa, 6(2), 252-280. 
Pasquaré, A. (2015). Los ego documentos en la formación de redes intelectuales americanistas a comienzos de siglo XX. En Jensen, S., Pasquaré, A. y Di Gresia, L. (eds.) Fuentes y archivos para una nueva Historia socio-cultural. Bahía Blanca: Hemisferio Derecho.

Peluffo, A. y Maíz, C. (2018). Presentación Dossier: afecto, redes y epistolarios. Landa, 6(2), 132-139.

Petrina, A. (2008). El neocolonial. Memoria y nostalgia de la raíz hispanoamericana. Summa, 96.

Rigotti, A. M. (2011). "Monumento a la Bandera en Rosario. Síntesis de búsquedas excéntricas en la modernidad argentina". Ponencia presentada en las Primeras Jornadas de Historia y Cultura de la Arquitectura y la ciudad. Grandes obras de la arquitectura en la Argentina (1910-1980), Universidad Torcuato Di Tella.

Rojas, R. (1924). Eurindia. Buenos Aires: La Facultad. . (1930). Silabario de la decoración americana. Buenos Aires: La Facultad.

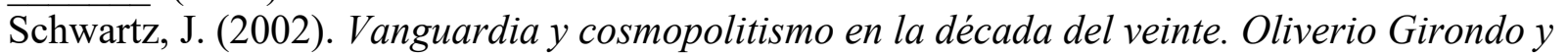
Oswald de Andrade. Rosario: Beatriz Viterbo

Saiz Cerreda, P. (2002). La dimensión dialogística de la carta: una lectura del pacto epistolar en la correspondencia de Antoine de Saint-Exupéry. Cuaderno de investigación filológica de la Universidad de La Rioja, 27-28, 307-322. . (2006). El diálogo en la carta: una cláusula del pacto para la construcción de un espacio epistolar (pp. 227-236). En AAVV. Espacio y texto en la cultura francesa. Alicante: Universidad de Alicante.

Terán, O. (2000). El pensamiento finisecular, 1880-1916. En M. Lobato (Dir.). Nueva Historia Argentina. Buenos Aires: Sudamericana.

Viñas, D. (2005). Literatura argentina y política. II. De Lugones a Walsh. Buenos Aires: Santiago Arcos. 